\title{
Ultrasonographic Assessment of Entheseal Sites of Upper and Lower Extremities in Hemodialysis Patients using Madrid Sonography Enthesitis Index
}

\section{Reham Sabry}

Nephrology unit, Internal Medicine Department, Mansoura New General Hospital, The Egyptian Ministry of Health

\section{Samar Tharwat ( $\nabla$ samartharwat2000@yahoo.com )}

Rheumatology \& Immunology Unit, Internal Medicine Department, Faculty of Medicine, Mansoura University

\section{Mohammed Kamal Nassar}

Mansoura Nephrology \& Dialysis Unit (MNDU), Department of Internal Medicine, Faculty of Medicine, Mansoura University, Mansoura

\section{Ehab E Eltoraby}

Rheumatology \& Immunology Unit, Internal Medicine Department, Faculty of Medicine, Mansoura University

\section{Research Article}

Keywords: Ultrasonography, Enthesitis, Enthesopathy, Hemodialysis, MASEl score

Posted Date: November 16th, 2021

DOI: https://doi.org/10.21203/rs.3.rs-1065093/v1

License: (c) (1) This work is licensed under a Creative Commons Attribution 4.0 International License. Read Full License 


\section{Abstract}

\section{Background}

Musculoskeletal (MSK) complications are one of the most common health concerns that impact individuals on maintenance hemodialysis (HD). However, little is known about the entheseal involvement in HD patients. The aim of this study was to assess the prevalence and distribution of entheseal ultrasonographic (US) alterations in HD patients and to evaluate the association between US findings and both clinical and laboratory data.

Methods: This study was conducted on $41 \mathrm{HD}$ and 23 sex- and age- matched controls. All HD patients and healthy controls were evaluated clinically to detect any clinical evidence of enthesopathy. Six entheses sites were scanned bilaterally using grey scale (GS) and power Doppler (PD) ultrasonography (US) and were scored using Madrid Sonography Enthesitis Index (MASEI) scoring system.

\section{Results:}

Clinical examination revealed at least one sign suggestive of enthesopathy in 69 (14.02) of 492 entheses in $41 \mathrm{HD}$ patients. HD patients had statistically significant higher scores of stuctural tendon abnormalities $(p<0.001)$, enthesis thickening $(p<0.001)$, bone erosions $(p<0.001)$ and calcification $(p=0.037)$ than healthy controls. Total MASEl score was higher in HD patients than healthy controls (median ; 18 vs $8, p<0.001$ ), also, MASEl-inflammatory (median; 11 vs $3, p<0.001$ ) and damage scores (median ; 6 vs $0, p<0.001$ ). There was a statistically significant positive association between total MASEI score and both age $(p=0.032)$ and duration of HD $(p=0.037)$. Duration of HD was predictive for both MASEI-damage component $(p=0.004)$ and total MASEl score $(p=0.014)$.

\section{Conclusions:}

There is a high prevalence of asymptomatic enthesopathy in HD patients. The burden of entheseal US alterations is much higher in HD patients than in healthy subjects. US can be helpful in the early detection of entheseal abnormalities. The duration of HD is the most significant predictor of enthesopathy in HD patients.

\section{Introduction}

Chronic kidney disease (CKD) affects about $10-15 \%$ of adults worldwide [1]. And therefore, end stage kidney disease (ESKD) represents a global-health and health-care burden that is rapidly increasing [2]. The high prevalence of diabetes mellitus, hypertension, obesity, and ageing are all contributing to the global rise in this condition [3]. Dialysis is a form of renal replacement therapy that ensures maintenance of homeostasis in patients with ESRD [4]. Currently, dialysis is life-saving to nearly 3.4 million people with ESRD around the world [5]. Hemodialysis (HD), peritoneal dialysis, and hemofiltration are the three main forms of dialysis [6]. 
Although HD can reduce morbidity and mortality in renal patients, it can also cause a number of complications during dialysis sessions and/or as a result of long-term HD use [7]. Amyloidosis, bone disease, endocrine abnormalities, infection and cardiovascular complications are all risks associated with long-term HD [7]. Musculoskeletal (MSK) complications are one of the most common health concerns that impact individuals on maintenance HD [8]. Bone cysts, destructive arthropathy, amyloidosis, carpal tunnel syndrome, and spontaneous tendons rupture are some of these MSK complications $[9,10]$.

In HD patients, spontaneous ruptures of the Achilles and/or quadriceps tendon have been documented on a sporadic basis and are usually viewed as isolated events [11]. The reasons that predispose to such ruptures are still unknown. Some researchers believe that the tendon is still intact and that the rupture is caused by osteolytic bone resorption at the enthesis [12]. Enthesis is the area where ligaments, tendons, or joint capsules attach to bone [13].

Ultrasonography (US) is a widely available, noninvasive, reproducible, low-cost imaging modality that does not expose patients to ionizing radiation and can be used to diagnose, monitor, and stratify enthesopathy. When it comes to diagnosing enthesopathy, US is more sensitive than clinical examination, demonstrating a high frequency of abnormal findings even in asymptomatic patients [14]. However, little information is known about the entheseal involvement in HD patients; only few studies have been carried out to assess if HD patients have a 'subclinical' enthesopathy $[15,16]$.

Therefore, the aim of this study was to evaluate the frequency and distribution of entheseal US alterations in HD patients and to evaluate the association between US findings and both clinical characteristics and laboratory data.

\section{Materials And Methods}

\section{Study population}

This cross-sectional observational study was carried out from October 2017 to March 2020 on 41 patients with ESRD and receiving HD at Mansoura Nephrology and Dialysis Unit, Mansoura University Hospital, Egypt. The sample size was selected as a convenience sample. All patients who met the inclusion criteria were offered to participate in the study unless they qualify for any of the exclusion criteria or refuse to participate. Inclusion criteria included ESRD patients aged more than 18 years and undergoing HD for more than 6 months, three times per week. Patients who had a history of rheumatic or autoimmune diseases, diabetes mellitus, peripheral neuropathy, chronic use of steroids and/ or fluoroquinolone therapy during the previous 6 months, sever trauma or joint surgery were excluded from the study. Twenty-three age- and sex matched healthy controls were also included. The study was performed in accordance with the Declaration of Helsinki. It was approved by the Institutional Research Board of the Faculty of Medicine, Mansoura University (Approval number:MS/17.05.120). The study was explained to all participants, and informed written consent was obtained from all of them before starting the study. 


\section{Data collection}

Demographic data including age, sex, occupation, and marital status were recruited. Body weight was measured. Other clinical parameters (e.g., vascular access side and HD duration) were obtained from each HD patient through an interview.

\section{Clinical evaluation of different entheseal sites}

Clinical evaluation was conducted to all HD patients and healthy controls by an expert rheumatologist to detect any clinical signs indicative of enthesopathy. These signs included swelling or tenderness elicited by mobilization, pressure,and contraction against resistance of the corresponding entheses.

\section{Madrid Sonographic Enthesis Index (MASEI) Scoring System}

All US examinations were carried out by a rheumatologist with at least 7 years of experience in the field of musculoskeletal ultrasound (MSUS). At the time of US evaluation, the rheumatologist was blind to the clinical assessment of the entheseal sites. The EDAN U2 ultrasound equipment (Shenzhen, China) with a linear array transducer was employed in the study ( 8 to $13.4 \mathrm{MHz}$ ). The frequency was set to $13 \mathrm{MHz}$, and the sonographic settings were adjusted to provide the best images of the scanned enthesis. With a constant room temperature of $21 \mathrm{C}$ and a lower wall filter, power Doppler (PD) settings were standardized with a pulse repetition frequency (PRF) of $0.75-1.20 \mathrm{kHz}$ and a PD gain of $50-55 \mathrm{~dB}$.

Six entheses were scanned bilaterally in axial and longitudinal planes as specified by de Miguel [17]. The scanned entheseal sites included the following: proximal plantar aponeurosis, distal Achilles' tendon, distal and proximal patellar ligament insertion, distal quadriceps tendon and distal triceps tendon. Entheses were scored using the Madrid Sonography Enthesitis Index (MASEI) scoring system [17].The elementary lesions included thickness, structural tendon abnormalities, enthesis thickening, bone erosions, calcification, PD and bursitis.

Additionally, analysis 2 subscores of MASEl were included; the MASEl-inflammatory (structural tendon abnormalities, enthesis thickening, PD and bursitis) and MASEl-damage (calcifications, enthesophytes, and erosions) [18].

\section{Blood sampling and laboratory tests}

Just before starting the first HD session of the week, blood samples were taken from the vascular access of HD patients. An automated analyzer was used to perform laboratory tests on the days of blood sampling. Laboratory tests included complete blood count (CBC), total cholesterol, triglycerides, serum calcium, phosphorus, parathyroid hormone level (PTH) and uric acid.

\section{Statistical analysis}


Data were collected and analyzed using IBM SPSS Statistics version 24.0 for Windows (IBM Corp., Armonk, NY, USA) on a personal computer. For all quantitative values, medians (interquartile range [IQR] or 25th percentile -75 th percentile) or means \pm standard deviation were used, while numbers of cases and percentages (\%) were utilized to illustrate qualitative variables. The Shapiro-Wilk test was used to check for normality in the distribution of continuous variables and the significance of differences between the two groups was assessed by the independent samples $t$ test for normally distributed variables or by the Mann-Whitney test for non-parametric variables. For comparisons between qualitative variables, Chi-square or Fisher exact tests were utilized, as appropriate. Correlation analysis using the Spearman's test were used to define relevant factors that affected MASEI scores. Subsequently, univariate linear regression analysis was done to assess the predictors of MASEI scores. $P$ value less than 0.05 was considered significant.

\section{Results}

\section{Study_population}

The study included a total of $41 \mathrm{HD}$ patients (mean age $50.7 \pm 14.5$ years, 25 males and 16 females) and 23 healthy sex- and age-matched controls (mean age $45.3 \pm 8.9$ years, 14 males and 9 females). We scanned 492 entheses sites in HD patients and 276 in healthy controls. Table 1 shows the clinical characteristics and laboratory data of HD patients and healthy controls. For the HD group, the median duration since onset of HD was 4 years. Majority of patients (80.5\%) had vascular access at the right side.

\section{Clinical evaluation of different entheseal sites}

Clinical examination revealed at least one sign suggestive of enthesopathy in 69 (14.02\%) of 492 entheses in $41 \mathrm{HD}$ patients. Of which, the most frequently involved entheseal site was proximal patellar ligament (19.5\%) followed by quadriceps tendon (18.3\%) while the least involved was triceps tendon enthesis (2.4\%). No clinical evidence of enthesopathy was detected in healthy controls. Figure 1 shows the distribution of entheseal sites that clinically involved in HD patients.

\section{Madrid Sonographic Enthesis Index (MASEl) Scoring System}

Table 2 illustrates the morphostructural changes of each enthesis according to MASEl scoring system. HD patients had significantly higher thickness and structural tendon abnormalities at almost all scanned entheseal sites when compared to healthy individuals.

Table 3 shows the total MASEl scores of each component and each enthesis in HD patients and healthy subjects. There were statistically significant higher scores of structural tendon abnormalities $(p<0.001)$, 
enthesis thickening $(p<0.001)$, bone erosions $(p<0.001)$ and calcification $(p=0.037)$ in HD patients when compared with healthy subjects. Also, total MASEl score of each enthesis was significantly higher in HD patients in comparison to healthy subjects. HD patients had significantly higher total MASEl score than healthy controls (median ; 18 vs $8, p<0.001$ ), also higher MASEl-inflammatory (median ; 11 vs $3, p<0.001$ ) and damage scores (median ; 6 vs $0, p<0.001$ ).

Of a total 492 scanned entheseal sites in $41 \mathrm{HD}$ patients, the highest number of elemental lesions seen was enthesis thickening $(272 / 492,55.3 \%)$, followed by structural tendon abnormalities $(158 / 492,32.1 \%)$, calcification $(69 / 492,14 \%)$, bone erosions $(66 / 492,13.4 \%)$, bursitis $(14 / 492,2.8 \%)$ and power Doppler signal (40/492,8\%) as shown in table 4.

\section{Correlation between MASEl scores and clinico-laboratory. data}

As shown in table 5 , there was a statistically significant positive association between total MASEl score and both age $(p=0.032)$ and duration of HD ( $p=0.037)$. However, no statistically significant correlation was found between total MASEI, MASEl-inflammatory, and MASEI-damage sores and the following variables: body weight, total cholesterol, serum calcium, phosphorous and parathyroid hormone levels.

\section{Predicting MASEI scores in HD patients}

Univariate regression analyses revealed the following data: age was predictive for MASEl-inflammatory component $(p=0.042)$ while duration of HD was predictive for both MASEI-damage component $(p=0.004)$ and total MASEl score $(p=0.014)$ as illustrated in table 6 .

\section{Discussion}

MSK manifestations are common in patients on long-term HD, with reported frequency up to $70 \%$ [19], most of which are attributable to amyloid deposition [19]. Amyloid deposits in a variety of tissues, with a higher proclivity for bone and synovial membranes. Additionally, tendons and peripheral nerves can be impacted by this serious condition [20].

Enthesitis is a common feature of spondylarthritis [21]. However, the clinical examination and radiology used to evaluate entheses are not reliable nor accurate [22]. High-resolution US is commonly employed as an imaging tool in the diagnosis of enthesopathy [23].Subclinical entheseal involvement in HD patients has not been deeply investigated [15]. As a result, this study was carried out to identify entheseal involvement in HD patients using MASEl scoring system. Gutierrez and coworkers conducted a similar study utilizing Glasgow Ultrasound Enthesitis Scoring System (GUESS), although it does not include PD evaluation or upper limb enthesis characteristics [15]. 
Our study sheds new light on the topography and prevalence of entheseal involvement in HD patients. To the best of our knowledge, this is the first to use MASEl scoring system in HD patients. Six entheseal sites were scanned using both GS and PDUS. Clinical examination revealed at least one sign suggestive of enthesopathy in 69 (14.02\%) of 492 entheses in $41 \mathrm{HD}$ patients. Musculoskeletal US revealed that tendon and ligament thicknesses were significantly higher in HD patients in comparison to healthy controls. Total MASEl score was positively correlated with both age and duration of HD. Age was predictive for MASEI-inflammatory component while duration of HD was predictive for both MASEl-damage component and total MASEl score.

MSUS can effectively screen for subclinical enthesopathy [24]. Chronic subclinical enthesopathy may diminish tendon mechanical resistance, thus representing a potential risk factor for tendon rupture in the future [25]. In the current study, clinical examination revealed at least one sign suggestive of enthesopathy in 69 (14.02\%) of 492 entheses in $41 \mathrm{HD}$ patients, which is much lower than that detected by US (68.9\%). A similar pattern of results was obtained in another study, in which, US signs of enthesopathy were detected in $50 \%$ of the scanned entheseal sites in dialysis patients [15]. A high prevalence of subclinical enthesopathy has also been recognized in Behçet's disease [26], Sjögren syndrome [27], fibromyalgia [27], psoriasis[28] and systemic sclerosis [29].

In this study, there were statistically significant higher scores of structural tendon abnormalities, enthesis thickening, bone erosions and calcification in HD patients when compared with healthy subjects. HD patients had significantly higher total MASEI score than healthy controls, also higher MASEIinflammatory and damage scores. Overall these findings are in accordance with findings reported by Gutierrez and colleages in a study conducted on 33 dialysis patients and 33 healthy controls adopting Glasgow Ultrasound Enthesitis Scoring System (GUESS) scoring system and demonstrated a higher prevalence of enthesopathy in dialysis patients than in healthy subjects [15].Tendon abnormalities in the form of calcific deposition, increased thickness and abnormal peritendon tissue have also been documented in another study, in which, quadriceps and Achilles tendons were evaluated in $50 \mathrm{HD}$ patients by MSUS [30].

Our results demonstrate a statistically significant positive association between total MASEl score and both patients' age and duration of HD. A similar conclusion was reached by another study [15]. Age may influence the biological milieu and tendon adaptation to mechanical loading [31]. Additionally, long-term dialysis has been linked to MSK problems, including bone cysts, amyloidosis, destructive arthropathy, carpal tunnel syndrome, and spontaneous tendon rupture [32]. Contrary to the findings of Falsetti and colleagues [33], we did not find a significant association between total MASEl score and body weight.

Tendon degeneration is often caused by metabolic disorders (e.g. diabetes, hyperuricemia, or hypercholesterolemia) [31]. Hypercholesterolemia may be associated with abnormal tendon thickness or structure [34]. However, no correlation was found between MASEl scores and total cholesterol level in our cohort. 
Significant osteolytic bone resorption with osteoclasts at the point of tendon insertion has been described in hyperparathyroidism in HD patients [35]. Secondary hyperparathyroidism may lead to tendon rupture due to changes that occur at the tendo-osseous junction [36]. Even though, our results suggest no correlation between MASEI scores and PTH level.

Using univariate linear regression analysis, age was predictive for MASEl-inflammatory component. This is consistent with what has been found in a recent study [37], they investigated the contributing factors of US lesions of entheses in healthy subjects and found that age predicted not only inflammation, but also, damage and total US enthesopathy scores. While the ability of the tendons to compensate for stress is preserved in youth, impaired resilience of aged tissues is connected to cellular senescence and changes in extracellular matrix mechanical properties [38].

One of the strengths of this study is that it represents a comprehensive scanning of entheses at both upper and lower limbs in HD patients. Also, a control group of sex- and age-matched participants was included.

However, our study has some limitations: firstly, the relatively small sample size. Secondly, the crosssectional nature resulting in only a single evaluation of the entheses with absence of long-term follow-up. Finally, only one sonographer was utilized; a second sonographer would aid in determining the reproducibility of findings because US is an operator-dependent examination with possible inter-observer variability. A future study's goal would be to determine inter and intra reader variability.

To the best of our knowledge, this is the first study to use the MASEl scoring system to detect enthesopathy in HD patients.

\section{Conclusions}

There is a high prevalence of asymptomatic subclinical enthesopathy in both upper and lower limbs in HD patients. Additionally, the burden of entheseal US alterations is much higher than in healthy subjects. MSUS can be helpful in the early detection of entheseal abnormalities in HD patients. The duration of HD is the significant predictor of enthesopathy in these patients. Finally, entheseal involvement in HD patients do not correlate with PTH or serum calcium level. The current findings need to be replicated in other ethnic groups and with a larger sample size.

\section{Abbreviations}

CKD: chronic kidney disease

ESKD: end stage kidney disease

GS: grey scale

GUESS: Glasgow Ultrasound Enthesitis Scoring System 
HD: hemodialysis

MASEl: Madrid Sonography Enthesitis Index

MSK: musculoskeletal

MSUS: musculoskeletal ultrasound

PD: power Doppler

PRF: pulse repetition frequency

PTH: parathyroid hormone

US: ultrasonographic

US: ultrasonography

\section{Declarations}

\section{Ethics approval and consent to participate}

No parts of the final version of the manuscript contain copied parts and all co-authors take full responsibility for the integrity of the published article. The study was performed in accordance with the Declaration of Helsinki. It was approved by the Institutional Research Board of the Faculty of Medicine, Mansoura University (Approval number: MS/17.05.120). The study was explained to all participants, and informed written consent was obtained from all of them before starting the study.

\section{Consent for publication}

N/A

\section{Availability of data and materials}

All data generated or analyzed during this study are included in this published article or are available from the corresponding author on reasonable request.

\section{Competing interests}

All authors have no conflicts of interest to declare. 


\section{Funding}

$\mathrm{N} / \mathrm{A}$

\section{Authors' contributions}

Conceptualization: RS, ST, EE Investigation, all authors Data curation, formal analysis: RS, ST, MK, writing-original draft: ST, EE, writing-review \& editing: All authors

\section{Acknowledgments}

Not applicable

\section{Authors' information (optional)}

RS, Specialist, https://orcid.org/0000-0002-3940-2168

ST, Associate professor, https://orcid.org/0000-0001-9892-2449

MKN, Associate professor, https://orcid.org/0000-0002-5124-2507

EEE, Professor, https://orcid.org/0000-0003-4183-7475

\section{References}

1. Coresh J, Selvin E, Stevens LA, Manzi J, Kusek JW, Eggers P, et al. Prevalence of chronic kidney disease in the United States. JAMA. 2007;298(17):2038-47.https://doi.org/ 10.1001/jama.298.17.2038.

2. Thurlow JS, Joshi M, Yan G, Norris KC, Agodoa LY, Yuan CM, et al. Global epidemiology of end-stage kidney disease and disparities in kidney replacement therapy. Am J Nephrol.2021;52(2):98-107. https://doi.org/ 10.1159/000514550.

3. Thomas MC, Cooper ME, Zimmet PJNRN. Changing epidemiology of type 2 diabetes mellitus and associated chronic kidney disease. Nat Rev Nephrol. 2016;12(2):73-81. https://doi.org/ 10.1038/nrneph.2015.173.

4. Canaud B, Collins A, Maddux FJNDT. The renal replacement therapy landscape in 2030: reducing the global cardiovascular burden in dialysis patients. Nephrol Dial Transplant. 2020;35(Supplement_2):ii51-ii7. https://doi.org/ 10.1093/ndt/gfaa005.

5. Stenvinkel P, Fouque D, Wanner C. Life/2020-the future of kidney disease. Oxford University Press; 2020. https://doi.org/ 10.1093/ndt/gfaa028. 
6. Nitta K, Goto S, Masakane I, Hanafusa N, Taniguchi M, Hasegawa T, et al. Annual dialysis data report for 2018, JSDT Renal Data Registry: Survey methods, facility data, incidence, prevalence, and mortality. Ren Replace Ther.2020;6(1):1-18. https://doi.org/ 10.1186/s41100-020-00286-9.

7. Scarpioni R, Ricardi M, Albertazzi V, De Amicis S, Rastelli F, Zerbini LJljon, et al. Dialysis-related amyloidosis: challenges and solutions. Int J Nephrol Renovasc Dis. 2016;9:319. https://doi.org/10.2147/IJNRD.S84784.

8. Ezzat S, Tharwat S, Abdelsalam S, Eltoraby EEJBp. Musculoskeletal Symptoms in Hemodialysis Patients and their Effect on Health-Related Quality of Life. Blood Purif.2020;49(3):289-94. https://doi.org/ 10.1159/000504038.

9. Kiss E, Keusch G, Zanetti M, Jung T, Schwarz A, Schocke M, et al. Dialysis-related amyloidosis revisited. AJR Am J Roentgenol.2005;185(6):1460-7. https://doi.org/ 10.2214/AJR.04.1309.

10. Tharwat S, Nassar MKJKR, Practice C. Clinical and ultrasonographic screening for carpal tunnel syndrome in hemodialysis patients. Kidney Res Clin Pract. 2020;39(2):213. https://doi.org/ 10.23876/j.krcp.20.011.

11. Kandemir NG, Aydın E, Yalbuzdağ ŞA, Şengül İ, Kurtulmuş A, Kaya T, et al. Bilateral Quadriceps and Concomitant Unilateral Triceps Tendon Rupture in a Chronic Hemodialysis Patient. Turk Osteoporoz Dergisi.2018;24(3):104. https://doi.org/ 10.4274/tod.galenos.2018.34635.

12. Wani N, Malla H, Kosar T, Dar IJljon. Bilateral quadriceps tendon rupture as the presenting manifestation of chronic kidney disease. Indian J Nephrol. 2011;21(1):48. https://doi.org/ 10.4103/0971-4065.78079.

13. Liew MY, Mortimer JW, Paxton JZ, Tham S, Rust PAJJoWS. Histomorphology of the Subregions of the Scapholunate Interosseous Ligament and Its Enthesis. J Wrist Surg. 2021. https://doi.org/ 10.1055/s-0041-1723792.

14. Zuliani F, Zabotti A, Errichetti E, Tinazzi I, Zanetti A, Carrara G, et al. Ultrasonographic detection of subclinical enthesitis and synovitis: a possible stratification of psoriatic patients without clinical musculoskeletal involvement. Clin Exp Rheumatol. 2019;37(4):593-9.

15. Gutierrez M, Zeiler M, Filippucci E, Salaffi F, Becciolini A, Bertolazzi C, et al. Sonographic subclinical entheseal involvement in dialysis patients. Clin Rheumatol 2011;30(7):907-13. https://doi.org/ 10.1007/s10067-011-1703-8.

16. Lin $\mathrm{CH}$, Shiang JC, Tsai MK,Chang CC, Chang DM. Sonographic Evaluation of Lower-limbs Entheses in Subclinical Patients Undergoing Hemodialysis. Formosan Journal of Rheumatology. 2012;26(1\&2):41-8.

17. de Miguel E, Cobo T, Muñoz-Fernández S, Naredo E, Usón J, Acebes JC, et al. Validity of enthesis ultrasound assessment in spondyloarthropathy. Ann Rheum Dis. 2009;68(2):169-74. https://doi.org/ 10.1136/ard.2007.084251.

18. Macía-Villa C, Cruz Valenciano A, De Miguel EJIJoRD. Enthesis lesions are associated with X-ray progression in psoriatic arthritis. Int J Rheum Dis. 2021;24(6):828-33. https://doi.org/ 10.1111/1756-185X.14122. 
19. Akasbi N, Houssaini TS, Tahiri L, Hachimi H, El Maaroufi C, El Youbi R, et al. Rheumatic complications of long term treatment with hemodialysis. Rheumatol Int. 2012;32(5):1161-3. https://doi.org/ 10.1007/s00296-010-1756-z.

20. Kelly A, Apostle K, Sanders D, Bailey HJCJoS. Musculoskeletal pain in dialysis-related amyloidosis. Can J Surg. 2007;50(4):305.

21. Schett G, Lories RJ, D'Agostino M-A, Elewaut D, Kirkham B, Soriano ER, et al. Enthesitis: from pathophysiology to treatment. Nat Rev Rheumatol. 2017;13(12):731-41. https://doi.org/ 10.1038/nrrheum.2017.188.

22. D'Agostino M-AJCER. Enthesitis detection by ultrasound: where are we now. Clin Exp Rheumatol.2018;36(Suppl 114):127-30.

23. Zhu L, Chen P, Sun X, Zhang S. Musculoskeletal ultrasound for ankylosing spondylitis: A systematic review and meta-analysis. Medicine (Baltimore). 2021;100(18):e25822. https://doi.org/ 10.1097/MD.0000000000025822.

24. Vyas K, Jain SK, Mittal A, Kumar R, Saxena S, Malviya S. Sonographic Evaluation of Subclinical Enthesopathy in Patients of Chronic Plaque Psoriasis. Indian Dermatol Online J. 2020;11(4):580-5. https://doi.org/ 10.4103/idoj.IDOJ_446_18.

25. Di Matteo A, Filippucci E, Cipolletta E, Satulu I, Hurnakova J, Lato V, et al. Entheseal involvement in patients with systemic lupus erythematosus: an ultrasound study. Rheumatology (Oxford). AJR Am J Roentgenol. 2018;57(10):1822-9. https://doi.org/ 10.1093/rheumatology/key189.

26. Ozkan F, Cetin GY, Bakan B, Kalender AM, Yuksel M, Ekerbicer HC, et al. Sonographic evaluation of subclinical entheseal involvement in patients with Behçet disease. AJR Am J Roentgenol. 2012;199(6):W723-W9. https://doi.org/ 10.2214/AJR.12.8576.

27. Sag S, Sag MS, Tekeoglu I, Kamanlı A, Nas KJJoMU. Presence of enthesopathy in patients with primary Sjogren's syndrome: ultrasonographic study of a local cohort. J Med Ultrason. 2018;45(1):121-7. https://doi.org/ 10.1007/s10396-017-0802-9.

28. Moshrif A, Mosallam AJEjor. Subclinical enthesopathy in patients with psoriasis and its association with other disease parameters: a power Doppler ultrasonographic study. Eur J Rheumatol. 2017;4(1):24. https://doi.org/ 10.5152/eurjrheum.2017.16049.

29. Kilic E, Kilic G, Akgul O, Ozgocmen SJMr. Presence of enthesopathy demonstrated with ultrasonography in systemic sclerosis. Mod Rheumatol. 2015;25(5):731-6.https://doi.org/ 10.3109/14397595.2015.1019962

30. Hussein DA, El-Azizi NO, Meged AHA, Al-Hoseiny SA, Hamada AM, Sabry MHJCMIA, et al. Ultrasonographic tendon alteration in relation to parathyroid dysfunction in chronic hemodialysis patients. Clin Med Insights Arthritis Musculoskelet Disord. 2015;8:CMAMD. S20887.https://doi.org/ 10.4137/CMAMD.S20887.

31. Abate M, Schiavone C, Salini V, Andia IJR. Occurrence of tendon pathologies in metabolic disorders. Rheumatology (Oxford). 2013;52(4):599-608.https://doi.org/ 10.1093/rheumatology/kes395. 
32. Shiota E, Tsuchiya K, Yamaoka K, Kawano OJCO, Research R. Spontaneous major tendon ruptures in patients receiving long-term hemodialysis. Clin Orthop Relat Res. 2002;394:236-42.https://doi.org/ 10.1097/00003086-200201000-00028.

33. Falsetti P, Conticini E, Baldi C, Bardelli M, Cantarini L, Frediani BJRC. Diffuse Peripheral Enthesitis in Metabolic Syndrome: A Retrospective Clinical and Power Doppler Ultrasound Study. Reumatol Clin (Engl Ed) 2021.https://doi.org/ 10.1016/j.reuma.2020.12.005.

34. Abate M, Di Carlo L, Salini V, Schiavone CJCr. Metabolic syndrome associated to non-inflammatory Achilles enthesopathy. Clin Rheumatol. 2014;33(10):1517-22. https://doi.org/ 10.1007/s10067-0142524-3.

35. Chen C-M, Wang S-J, Wu S-S, Chu P, Huang G-SJJotFMA. Spontaneous rupture of the patellar and contralateral quadriceps tendons associated with secondary hyperparathyroidism in a patient receiving long-term dialysis. J Formos Med Assoc. 2006;105(11):941-5.https://doi.org/ 10.1016/S0929-6646(09)60180-7.

36. Tsourvakas S, Gouvalas K, Gimtsas C, Tsianas N, Founta P, Ameridis NJAoo, et al. Bilateral and simultaneous rupture of the triceps tendons in chronic renal failure and secondary hyperparathyroidism. Arch Orthop Trauma Surg. 2004;124(4):278-80. https://doi.org/ 10.1007/s00402-003-0628-3.

37. Bakirci S, Solmaz D, Stephenson W, Eder L, Roth J, Aydin SZJTJor. Entheseal changes in response to age, body mass index, and physical activity: an ultrasound study in healthy people. J Rheumatol. 2020;47(7):968-72.https://doi.org/ 10.3899/jrheum.190540.

38. Masi AT, Andonian B, van der Heijde DJTJoR. Biomechanical factors may be the main contributor to entheseal changes in normal adults. J Rheumatol. 2021;48(4):618-9. https://doi.org/ $10.3899 /$ jrheum.201296.

\section{Tables}

\section{Table 1}

Clinical characteristics and laboratory data of HD patients $(n=41)$ and healthy subjects $(n=23)$ 


\begin{tabular}{|c|c|c|c|}
\hline Characteristic & HD patients $(n=41)$ & Healthy subjects $(n=23)$ & $P$ \\
\hline Age (years) & $50.7 \pm 14.5$ & $45.3 \pm 8.9$ & 0.068 \\
\hline \multicolumn{4}{|l|}{ Sex } \\
\hline Males & $25(61 \%)$ & $14(60.9 \%)$ & \multirow[t]{2}{*}{0.993} \\
\hline Females & $16(39 \%)$ & $9(39.1 \%)$ & \\
\hline Body weight (Kg) & $73(63-78.8)$ & $77(70-80)$ & 0.266 \\
\hline \multicolumn{4}{|l|}{ Occupation } \\
\hline Not working & $22(53.7)$ & $18(78.3)$ & \multirow[t]{2}{*}{0.051} \\
\hline Working & $19(46.3)$ & $5(21.7)$ & \\
\hline \multicolumn{4}{|l|}{ Marital status } \\
\hline Single & $9(22)$ & $10(43.5)$ & \multirow[t]{2}{*}{0.053} \\
\hline Married & $32(78)$ & $13(56.5)$ & \\
\hline Duration of HD (years ) & $4(2-6)$ & - & - \\
\hline \multicolumn{4}{|l|}{ Vascular access } \\
\hline Right side & $8(19.5)$ & - & \multirow[t]{2}{*}{-} \\
\hline Left side & $33(80.5)$ & - & \\
\hline Hemoglobin (g/dL) & $9.9(9.2-10.9)$ & $\mathrm{N} / \mathrm{A}$ & - \\
\hline Cholesterol (mg/dL) & $110(93-130.5)$ & $\mathrm{N} / \mathrm{A}$ & - \\
\hline Triglycerides $(\mathrm{mg} / \mathrm{dL})$ & $73(63-10.4 .5)$ & $\mathrm{N} / \mathrm{A}$ & - \\
\hline Calcium (mg/dL) & $8.5(7-9.5)$ & $\mathrm{N} / \mathrm{A}$ & - \\
\hline Phosphorus (mg/dL) & $6(3.6-8.5)$ & $\mathrm{N} / \mathrm{A}$ & - \\
\hline PTH (pg/mL) & $518(207-1090.5)$ & $\mathrm{N} / \mathrm{A}$ & - \\
\hline Uric acid $(\mathrm{mg} / \mathrm{dl})$ & $6.4(5.4-7)$ & $\mathrm{N} / \mathrm{A}$ & - \\
\hline
\end{tabular}

Quantitative variables are expressed as mean \pm standard deviation for normally distributed data and median $\left(25^{\text {th }}\right.$ percentile $-75^{\text {th }}$ percentile) for non-normally distributed data. Qualitative variables are expressed as number (\%)

PTH: parathyroid hormone

Table 2 
The morphostructural changes of each entheses according to Madrid Sonographic Enthesis Index (MASEI) Scoring System in HD patients $(n=41)$ and healthy subjects $(n=23)$ 


\begin{tabular}{|c|c|c|c|}
\hline Parameter & $\begin{array}{l}\text { HD patients } \\
(\mathrm{n}=41) \\
\text { Entheses (82) }\end{array}$ & 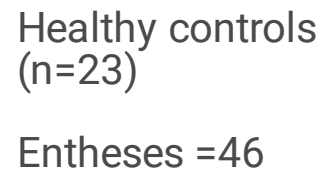 & $P$ \\
\hline \multicolumn{4}{|l|}{$\begin{array}{l}\text { Inferior pole of the calcaneus: plantar } \\
\text { aponeurosis enthesis }\end{array}$} \\
\hline Thickness,mm, median (IQR) & & (1) & 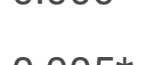 \\
\hline Stuctural tendon abnormalities ,n (\%) & $40(50.1)$ & $14(00.4)$ & $0.005^{\wedge}$ \\
\hline Enthesis thickening,n (\%) & $36(43.9)$ & $7(15.2)$ & $0.001^{\star}$ \\
\hline Bone erosions,n (\%) & $5(6.1)$ & $1(2.2)$ & 0.418 \\
\hline \multicolumn{3}{|l|}{ Calcification,n (\%) } & 0.104 \\
\hline Mild & $14(17.1)$ & $3(6.5)$ & \\
\hline Moderate & $3(3.7)$ & $5(10.9)$ & \\
\hline $\begin{array}{l}\text { Severe } \\
\text { Power Doppler signal,n (\%) }\end{array}$ & 0 & 0 & - \\
\hline \multicolumn{4}{|c|}{$\begin{array}{l}\text { Superior pole of the calcaneus: Achilles tendon } \\
\text { enthesis }\end{array}$} \\
\hline Thickness,mm, median (IQR) & & & 0.000 \\
\hline Stuctural tendon abnormalities ,n (\%) & $10(19.5)$ & $4(8.1)$ & 0.132 \\
\hline Enthesis thickening,n (\%) & $40(48.8)$ & $6(13)$ & 0.000 \\
\hline Retrocalcaneal bursitis & $10(12.2)$ & $3(6.5)$ & 0.375 \\
\hline Bone erosions,n (\%) & $10(12.2)$ & 0 & $0 . .014 *$ \\
\hline \multicolumn{4}{|l|}{ Calcification,n (\%) } \\
\hline Mild & & & \\
\hline Moderate & $0(9.0)$ & $\angle(4.3)$ & \\
\hline Severe & 0 & $1(2.2)$ & \\
\hline Power Doppler signal,n (\%) & 0 & 0 & - \\
\hline \multicolumn{4}{|c|}{ Tibial tuberosity: distal patellar ligament enthesis } \\
\hline Patellar ligament structure,n (\%) & $55(67.1)$ & $13(28.3)$ & $0.000 *$ \\
\hline Thickness,mm, median (IQR) & $4.45(1.6)$ & $3.4(0.85)$ & $0.000 *$ \\
\hline Stuctural tendon abnormalities ,n (\%) & $27(32.9)$ & $2(4.3)$ & $0.000^{\star}$ \\
\hline Enthesis thickening,n (\%) & $50(61)$ & $10(21.7)$ & $0.000 *$ \\
\hline
\end{tabular}




\begin{tabular}{|c|c|c|c|}
\hline Infrapatellar bursitis ,n (\%) & $4(4.9)$ & $2(4.3)$ & 1 \\
\hline Bone erosions,n (\%) & $7(8.5)$ & $1(2.2)$ & 0.257 \\
\hline \multicolumn{4}{|l|}{ Calcification,n (\%) } \\
\hline Mild & $4(4.9)$ & 0 & 0.401 \\
\hline Moderate & $2(2.4)$ & $1(2.2)$ & \\
\hline Severe & $1(1.2)$ & 0 & \\
\hline Power Doppler signal,n (\%) & 0 & 0 & - \\
\hline \multicolumn{4}{|c|}{$\begin{array}{l}\text { Inferior pole of the patella: proximal patellar } \\
\text { ligament enthesis }\end{array}$} \\
\hline Thickness,mm, median (IQR) & $18(22)$ & $4(8.7)$ & 0.086 \\
\hline Stuctural tendon abnormalities ,n (\%) & $55(67.1)$ & $13(28.3)$ & $0.000 *$ \\
\hline Enthesis thickening,n (\%) & $4(4.9)$ & $1(2.2)$ & 0.654 \\
\hline Bone erosions,n (\%) & & & \\
\hline \multicolumn{4}{|l|}{ Calcification,n (\%) } \\
\hline Mild & $1(1.2)$ & $1(2.2)$ & 0.093 \\
\hline Moderate & $1(1.2)$ & 0 & \\
\hline Severe & 0 & 0 & \\
\hline Power Doppler signal,n (\%) & 0 & 0 & - \\
\hline \multicolumn{4}{|c|}{$\begin{array}{l}\text { Superior pole of the patella: quadriceps tendon } \\
\text { enthesis }\end{array}$} \\
\hline Thickness,mm, median (IQR) & $6.4(1.7)$ & $6(1.53)$ & $0.002^{\star}$ \\
\hline & $36(43.9)$ & $9(19.6)$ & $0.006^{\star}$ \\
\hline Stuctural tendon abnormalities ,n (\%) & $56(86.3)$ & $19(41.3)$ & $0.003^{*}$ \\
\hline Enthesis thickening,n (\%) & $28(34.1)$ & $4(8.7)$ & $0.001 *$ \\
\hline Bone erosions,n (\%) & & & \\
\hline \multicolumn{4}{|l|}{ Calcification,n (\%) } \\
\hline Mild & $7(8.5)$ & $2(4.3)$ & 0.218 \\
\hline Moderate & $11(13.4)$ & $2(4.3)$ & \\
\hline menter & $1(1.2)$ & 0 & \\
\hline Power Doppler signal,n (\%) & $3(3.7)$ & 0 & 0.552 \\
\hline \multicolumn{4}{|c|}{ Olecranon tuberosity: triceps tendon enthesis } \\
\hline Thickness,mm, median (IQR) & $4.05(2.43)$ & $2.7(1.03)$ & $0.000 *$ \\
\hline
\end{tabular}




\begin{tabular}{llll|} 
Stuctural tendon abnormalities , $\mathrm{n}(\%)$ & $15(18.3)$ & $1(2.2)$ & $0.010^{*}$ \\
Enthesis thickening,n (\%) & $35(42.7)$ & 0 & $0.000^{*}$ \\
Bone erosions,n (\%) & $12(14.6)$ & $1(2.2)$ & $0.031^{*}$ \\
Calcification, $\mathrm{n}(\%)$ & & & .091 \\
Mild & $6(7.3)$ & 0 & \\
Moderate & $2(2.4)$ & 0 & 1 \\
$\quad 1(1.2)$ & 0 & \\
\hline
\end{tabular}

\section{Table 3}

The total MASEl scores of each component and each enthesis in HD patients $(n=41)$ and healthy subjects $(n=23)$ 


\begin{tabular}{|c|c|c|c|}
\hline Enthesis & $\begin{array}{l}\text { HD patients } \\
(\mathrm{n}=41) \\
\text { Entheses (82) } \\
\text { median (IQR) }\end{array}$ & 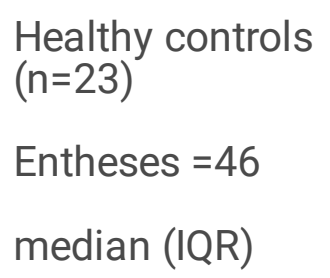 & $P$ \\
\hline $\begin{array}{l}\text { MASEl components score (maximum } \\
\text { score) } \\
\text { Stuctural tendon abnormalities (12) } \\
\text { Enthesis thickening (12) } \\
\text { Bursitis (4) } \\
\text { Bone erosions (36) } \\
\text { Calcification (36) } \\
\text { Power Doppler signal (36) }\end{array}$ & $\begin{array}{l}4(3) \\
7(3) \\
0(0) \\
3(6) \\
2(5) \\
0(0)\end{array}$ & $\begin{array}{l}1(3) \\
1(3) \\
0(0) \\
0(0) \\
0(2) \\
0(0)\end{array}$ & $\begin{array}{l}0.000 * \\
0.000 * \\
0.632 \\
0.000 * \\
0.037 * \\
0.187\end{array}$ \\
\hline Total MASEI score at : & & & \\
\hline Plantar aponeurosis enthesis & $3(4)$ & $0(4)$ & $0.015^{\star}$ \\
\hline Achilles tendon enthesis & $2(5)$ & $0(1)$ & $0.003^{*}$ \\
\hline Distal patellar ligament enthesis & $2(3)$ & $1(1)$ & $0.000 *$ \\
\hline Proximal patellar ligament enthesis & $2(2)$ & $1(1)$ & $0.001 *$ \\
\hline Quadriceps tendon enthesis & $4(7)$ & $1(3)$ & $0.000 *$ \\
\hline Triceps tendon enthesis & $1(3)$ & 0 & $0.000 *$ \\
\hline Total MASEI score & $18(11.5)$ & $4(8)$ & $0.000 *$ \\
\hline MASEI-inflammatory & $11(7)$ & $3(5)$ & $0.000 *$ \\
\hline MASEI-damage & $6(9)$ & $0(2)$ & $0.000 *$ \\
\hline
\end{tabular}

\section{Table 4}

Frequency of involvement of MASEl score components in HD patients $(n=41)$ and healthy subjects

$$
(n=23)
$$




\begin{tabular}{|c|c|c|c|}
\hline \multirow[t]{4}{*}{ MASEI score components } & HD patients & Healthy controls $(n=23)$ & \multirow[t]{4}{*}{$P$} \\
\hline & $(n=41)$ & Entheses $=276$ & \\
\hline & Entheses $=492$ & $\mathrm{n}(\%)$ & \\
\hline & $\mathrm{n}(\%)$ & & \\
\hline Stuctural tendon abnormalities & $158(32.1)$ & $34(12.3)$ & $0.000 *$ \\
\hline Enthesis thickening & $272(55.3)$ & $55(19.9)$ & $0.000 *$ \\
\hline Bursitis & $14(2.8)$ & $5(1.8)$ & 0.364 \\
\hline Bone erosions & $66(13.4)$ & $8(2.9)$ & $0.000 *$ \\
\hline Calcification & $69(14)$ & $18(6.5)$ & $.002 *$ \\
\hline Power Doppler signal & $4(0.8)$ & 0 & 0.303 \\
\hline Presence of one sign of enthesopathy & 339 (68.9) & $85(30.8)$ & $0.000 *$ \\
\hline
\end{tabular}

\section{Table 5}

Correlation between MASEI scores and clinico-laboratory data among HD patients $(\mathrm{N}=41)$

\begin{tabular}{|c|c|c|c|c|c|c|}
\hline \multirow[t]{2}{*}{ Variable } & \multicolumn{2}{|c|}{ MASEI-inflammatory } & \multicolumn{2}{|c|}{ MASEI-damage } & \multicolumn{2}{|c|}{ Total MASEI } \\
\hline & $r_{s}$ & $\mathbf{P}$ & $r_{s}$ & $\mathbf{P}$ & $\mathbf{r}_{\mathbf{s}}$ & $\mathbf{P}$ \\
\hline Age (years) & 0.297 & 0.059 & 0.261 & 0.099 & 0.336 & $0.032 *$ \\
\hline Sex & 0.216 & 0.175 & -0.064 & 0.693 & 0.055 & 0.733 \\
\hline Body weight $(\mathrm{Kg})$ & 0.128 & 0.427 & -0.057 & 0.725 & 0.029 & 0.855 \\
\hline Duration of HD (years ) & 0.171 & 0.284 & 0.341 & 0.029 & 0.327 & $0.037 *$ \\
\hline Associated comorbidities & -0.052 & 0.745 & 0.099 & 0.539 & 0.029 & 0.856 \\
\hline Hemoglobin (g/dL) & -0.205 & 0.199 & -0.240 & 0.130 & -0.216 & 0.176 \\
\hline Cholesterol (mg/dL) & -0.275 & 0.105 & 0.128 & 0.424 & -0.036 & 0.822 \\
\hline Triglycerides $(\mathrm{mg} / \mathrm{dL})$ & -0.106 & 0.510 & -0.112 & 0.485 & -0.134 & 0.403 \\
\hline Calcium (mg/dL) & -0.214 & 0.180 & 0.066 & 0.682 & -0.082 & 0.610 \\
\hline Phosphorus (mg/dL) & 0.047 & 0.770 & 0.284 & 0.072 & 0.139 & 0.385 \\
\hline PTH (pg/mL) & 0.139 & 0.386 & 0.076 & 0.639 & 0.131 & 0.414 \\
\hline Uric acid $(\mathrm{mg} / \mathrm{dl})$ & 0.106 & 0.511 & 0.147 & 0.358 & 0.138 & 0.388 \\
\hline
\end{tabular}


*P<0.05,PTH: Parathyroid hormone

\section{Table 6}

Univariate regression analysis to identify the predictors for MASEl scores among HD patients $(n=41)$

\begin{tabular}{|lllllll|}
\hline & \multicolumn{2}{l}{ MASEI-inflammatory } & \multicolumn{2}{l}{ MASEI-damage } & \multicolumn{2}{l|}{ Total MASEI } \\
\cline { 2 - 8 } Predictor variable & $\mathrm{B}$ & $\mathrm{P}$ & $\mathrm{B}$ & $\mathrm{P}$ & $\mathrm{B}$ & $\mathrm{P}$ \\
\hline Age (years) & 0.094 & $0.042^{\star}$ & 0.062 & 0.357 & 0.156 & 0.086 \\
\hline Duration of HD & 0.157 & 0.485 & 0.875 & $0.004^{\star}$ & 1.032 & $0.014^{\star}$ \\
\hline Hemoglobin level $(\mathrm{g} / \mathrm{dl})$ & -0.001 & 0.998 & -0.597 & 0.278 & -0.597 & 0.43 \\
\hline Serum cholesterol $(\mathrm{mg} / \mathrm{dl})$ & -0.021 & 0.164 & 0.010 & 0.639 & -0.011 & 0.716 \\
\hline Serum phosphorus $(\mathrm{mg} / \mathrm{dl})$ & 0.82 & 0.783 & 0.391 & 0.349 & 0.473 & 0.409 \\
\hline
\end{tabular}

${ }^{*} \mathrm{P}<0.05$

\section{Figures}

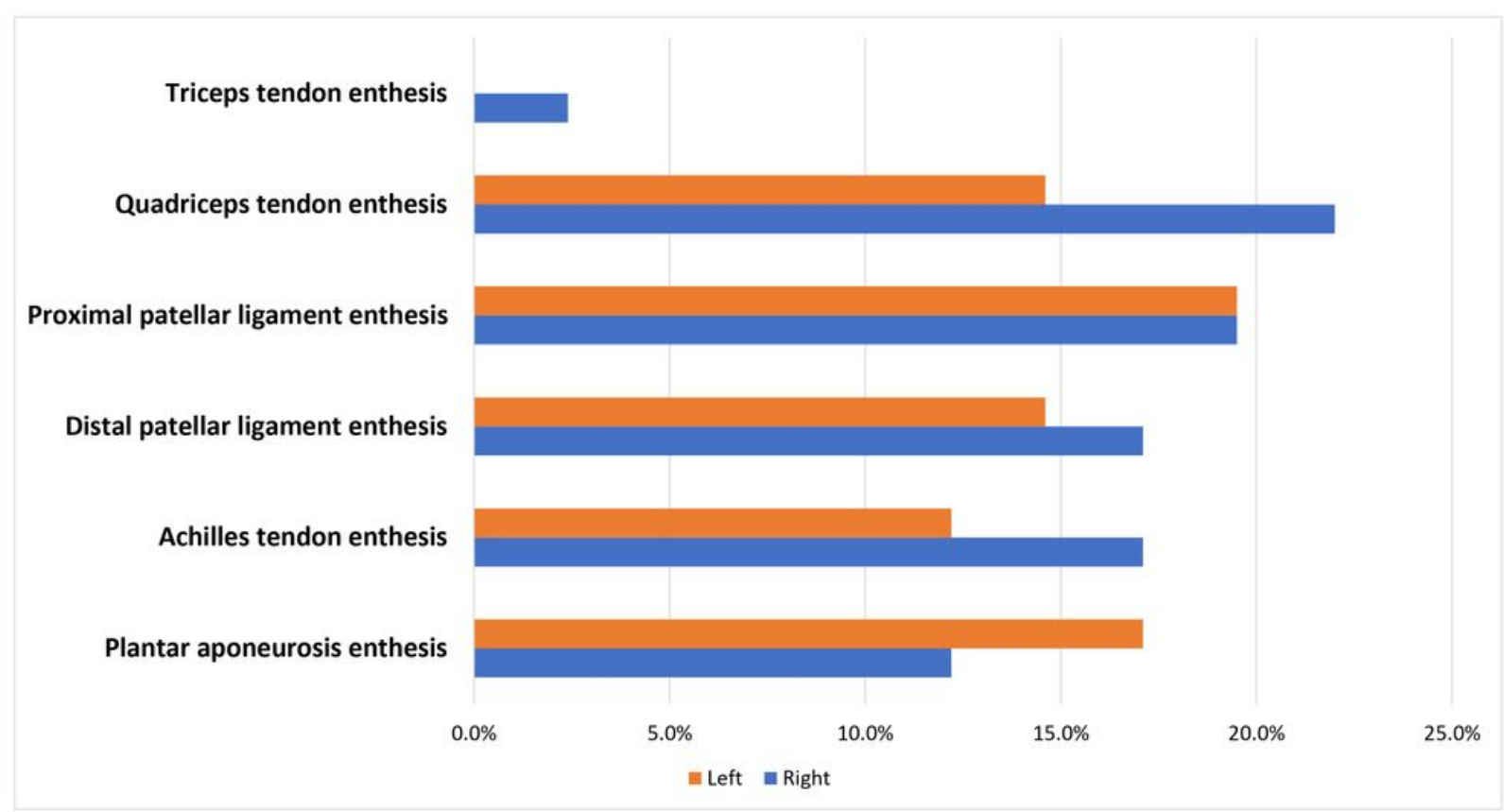

Figure 1 
Clinical evidence of enthesopathy at different entheseal sites in HD patients $(n=41)$

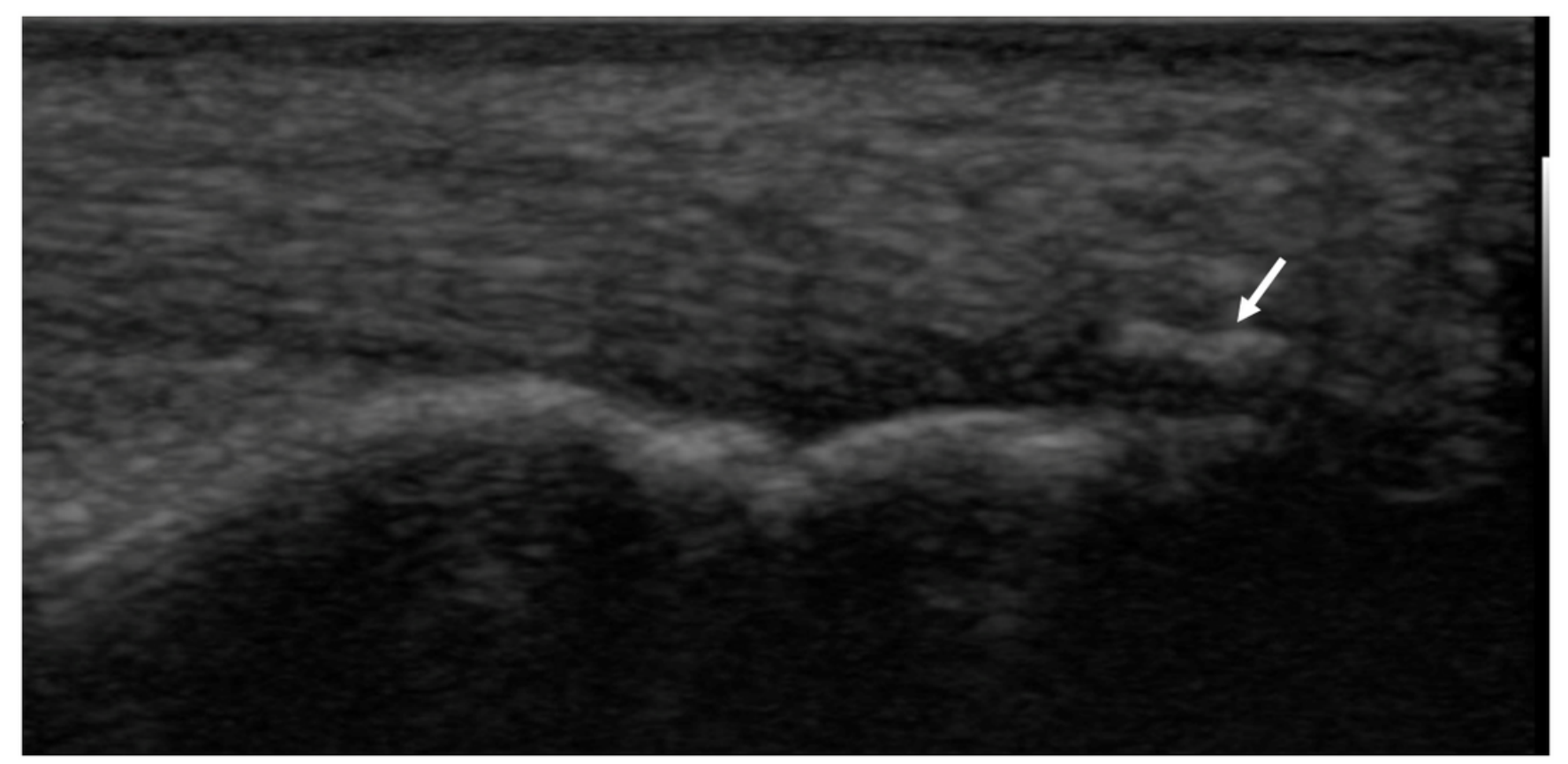

\section{Figure 2}

A 60-year-old female patient with chronic renal failure on chronic hemodialysis for 5years with calcification at the posterior pole of calcaneus enthesis 


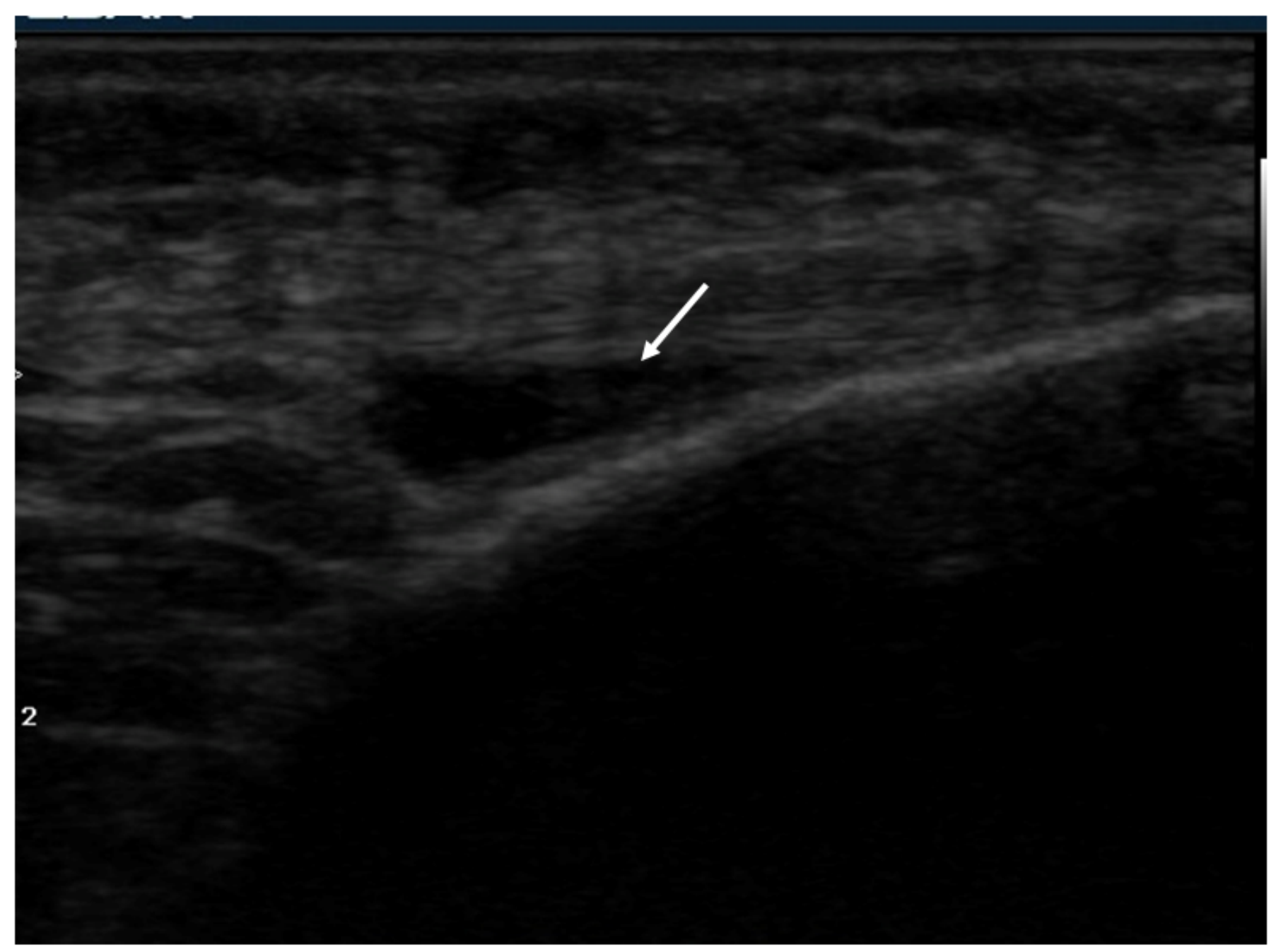

Figure 3

A 42-year-old male patient with chronic renal failure on chronic hemodialysis for 6 years with deep infrapatellar bursitis 


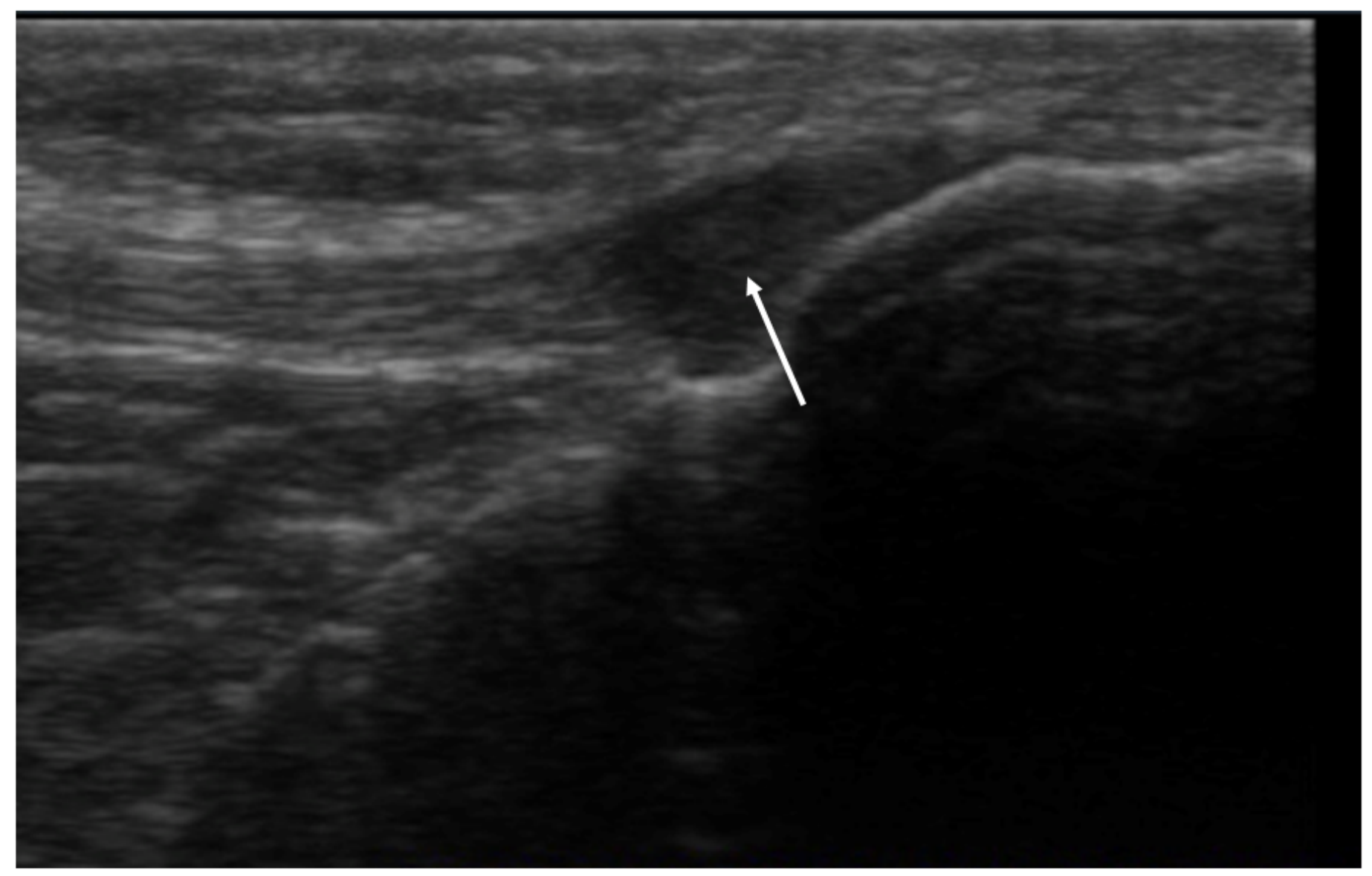

Figure 4

A 45-year-old female patient with chronic renal failure on chronic hemodialysis for 3 years with abnormal structure and hypoechoic pattern of the distal plantar ligament at its insertion at tibial tuberosity 